\title{
Patient empowerment in Europe: is no further research needed?
}

\author{
Livio Garattini ${ }^{1} \cdot$ Anna Padula $^{1}$
}

Published online: 8 March 2018

c) Springer-Verlag GmbH Germany, part of Springer Nature 2018

\section{Introduction}

In economic theory, health care can be considered a clear example of 'market failure' caused by lack of price competition, which does not enjoy the basic conditions to work on both the demand and supply sides; this justifies health economics as a discipline. From the demand side, patients have hardly ever been considered common consumers in European health-care systems and thus expenses have been mostly funded by 'third-party payers' at the macro level [1]. Therefore, physicians respond to 'payers' for health-care expenditure at the micro level and are supposed to establish a 'principal-agent relationship' with patients, deciding therapies on their behalf to fill the 'information asymmetry' gap.

The relationship between physicians and patients has been examined in other disciplines (e.g., philosophy, psychology and sociology), besides health economics. Trying to capture this multidisciplinary approach in the literature, we identified patient empowerment (PE) as possibly the oldest and still relevant concept used to describe a physician-patient relationship potentially alternative to that of health economics.

Here, after a brief outline of the historical background to PE, we summarize the flourishing contemporary literature around it, focusing on European articles. We then analyze the critical issues of the PE concept and finally discuss whether it can be really considered an alternative model to the principal-agent relationship identified by health economics.

Livio Garattini

livio.garattini@marionegri.it

1 CESAV, Centre for Health Economics, IRCCS Institute for Pharmacological Research "Mario Negri”, 24020 Ranica, Italy

\section{Patient empowerment}

\section{Historical background}

PE historically stems from the broader philosophical concept of empowerment [2] introduced by the Brazilian pedagog Freire in the 1970s. Born as a reaction to societal oppression and inequality, the term was soon adopted in other disciplines (starting with psychology), and transformed into a multidisciplinary concept [3]. Essentially, the idea of empowerment implies that any human being has the potential to make choices and gain control of her/his own life [4], Thus, personal abilities may be enhanced through social processes of behavior change, to help people meet their own needs [5].

Empowerment was linked with patients in health care for the first time in the early 1990s in the USA [6], to contrast the traditional medical model, which views the physician as the sole authority for treatment [7]. To challenge this paternalistic approach to health care, which tends to create a patient's dependence on the physician and ignore her/his personal preferences [8], PE promoted an ideological shift to increasingly patient-centered care [9], with redistribution of power from physicians toward patients [10]. Patients should be considered empowered once they have the knowledge, skills and attitudes necessary to influence their own behavior and improve the quality of their life [11]. This cultural change should imply a shift from passive 'compliance' (obedience) with physicians' directives [4] to active 'adherence' by agreeing on recommendations with health professionals (nurses included) [12].

The UK Government was the first in Europe to adopt the PE concept politically at the onset of the new millennium, promoting the idea of 'expert patients' [13] who should have full access to crucial information concerning their health.

\section{Literature search}

We searched the PubMed international database to select all the articles including PE in their title and published in 


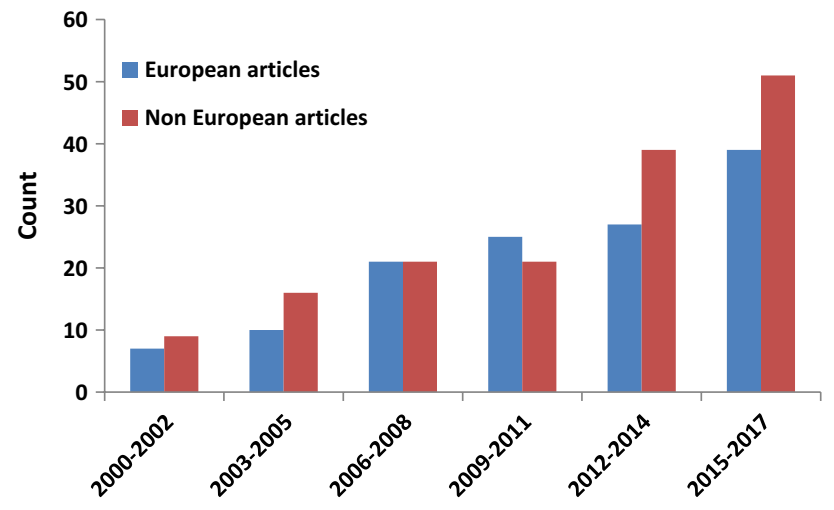

Fig. 1 Trend of articles including PE in the title

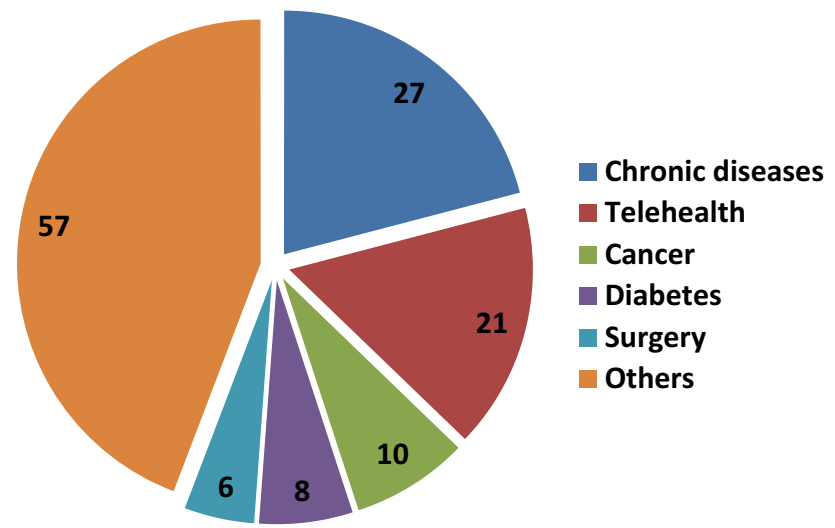

Fig. 2 European articles including PE in the title by subject (20002017)

this millennium (2000-2017), and found about 300. The trend has been rising steeply both worldwide and in Europe (Fig. 1). European articles ${ }^{1}$ have covered a wide range of subjects (Fig. 2) in different journals (Fig. 3), as could be predicted for a multidisciplinary concept such as PE.

\section{Definition, measure, terminology and disease}

According to the World Health Organization (WHO), $\mathrm{PE}$ is 'a process through which people gain greater control over decisions and actions affecting their health' [14]. Similarly, the European Network on Patient Empowerment (ENOPE) - a non-profit association established in 2012 to bring together organizations that implement PE programs across Europe-defines PE as 'a process to help people gain control, which includes people taking the initiative, solving

\footnotetext{
${ }^{1}$ Among the 129 European articles retrieved, 57 were clinical surveys and questionnaires, 33 editorials and commentaries, 29 reviews, and the remaining 10 various other.
}

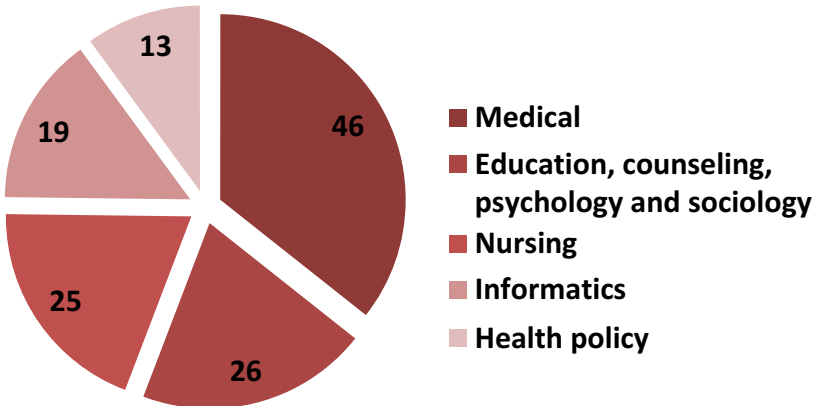

Fig. 3 European articles including PE in the title by type of journal (2000-2017)

problems, and making decisions' [15]. According to the latest European review [9], there are now 21 PE definitions worldwide ( 7 of them replicated by the same authors), while the penultimate review [3] had counted 17 a little earlier. The most frequently cited definitions hardly ever reached $10 \%$ of total quotations in PE studies according to another recent review [6].

Ten measures of PE as health outcome have also been recently identified in the literature [3], four from the USA, four from the UK, one from Canada and one from Iran. However, a previous review [16] found significant methodological shortcomings in the available measures, mainly due to a lack of clarity on the PE concept. Finally, despite all these efforts to improve PE definitions and measures, the latest (Canadian) review concluded that there is still a lack of conceptual clarity in PE research [17].

Meanwhile, in parallel to PE, many 'neighboring' concepts have been generated in the literature associated with the word 'patient', such as patient activation/centeredness/ engagement/enablement/involvement/participation, all originating from different disciplines [9]. These buzz concepts could be considered either synonymous or complementary to each other and/or PE, and their definitions are hardly stated explicitly in many studies [18].

Another concept often cited together and closely interwoven with PE is 'health literacy' [19], but here the relationship with PE seems clearer. Although a high level of health literacy is necessary to enhance PE [20], it is not enough because PE requires a behavioral change too [3]. As a consequence, a high level of health literacy without a corresponding high degree of PE still keeps patients unnecessarily dependent on physicians, while a high degree of PE without a corresponding degree of health literacy increases the risk of patients making dangerous health choices [19].

Another debated aspect of the PE concept concerns the types of illnesses and patients. Diabetes was the very first pathology to which PE was applied as a concept [21], probably not by chance, as this chronic disease has heavy effects on lifestyle and patients (by daily self-care) play a major role 
in managing their own health over the long term, with periodic contacts limited to primary care services whether well monitored [22]. Later, PE was applied to any condition, from rare to acute disease [23], although it would seem arguable, especially for the latter which are mainly treated in hospital. For instance, two surveys in coronary care units [24] and in palliative care for cancer [25] found that most patients were content to entrust their care to health professionals and had no desire to take part in decision-making.

Finally, PE is significantly affected by the general characteristics of patients too. For instance, older patients with a lower level of education may be less willing to challenge their physicians' authority [10].

\section{Discussion}

Our survey of the literature seems to confirm that PE has become a sort of umbrella concept for a wide range of activities and outcomes [26], as often happens with multidisciplinary approaches [27]. Its success seems due to both the political views of society and loss of confidence in healthcare professionals [28], especially physicians, who should 'come down off their pedestal' [29]. However, the claim that all types of patients should 'get up off their knees', assuming that only one role fits all patients, seems extreme [10]. Besides the borderline example of patients admitted to accident and emergency departments in very serious conditions, not all patients may wish to take charge of their own care and would still prefer to leave decisions in the physicians' hands. Accordingly, since the PE approach is based on mutual respect and a good physician-patient relationship [30], insisting on it for all patients might paradoxically become another model of paternalism [31]. Rather, the real challenge for clinicians (nurses included) should be to ascertain each patient's wishes, to understand what role she/he really wants to play [28], keeping in mind that power cannot be given, but can be taken $[10,32]$. Moreover, although clinicians are required to act in the best interest of their patients, competent patients might reject their recommendations, sometimes jeopardizing their health despite clinical evidence [33]. This raises an unavoidable ethical dilemma between a patient's rights to self-determination and the clinician's duties for care, a topic where it is hard to achieve a final consensus at any level [34].

To sum up, the argument that not all patients necessarily want to be empowered has apparently come full circle, starting from a challenge to paternalistic models of care [8]. However, we should not overlook PE's significant contribution toward more patient-centered health care that encourages openness and honesty, so clinicians and patients can freely discuss their views [35]. Facilitated by the Internet [36], power has been shifting in our society anyway [22], health care included. Although many physicians initially resisted the idea of increased PE, nowadays the general concept has become broadly accepted [37], and empowered patients mayhopefully-induce cost savings for health-care systems too $[23,38]$, especially for chronic diseases, through lower use of emergency and hospital services.

\section{Conclusion}

The PE concept has enriched the debate on the physician-patient relationship in the Internet era, while raising ethical implications regardless of the discipline adopted. Since this fascinating discussion goes far beyond our professional limits and the scope of this commentary, here we limit ourselves to our initial question whether PE can be considered an alternative to the approach provided by health economics.

Our literature survey suggests that PE is more a complementary model than an alternative to health economics. As underlined by many authors who have contributed to the debate on PE [39, 40], health care cannot be transformed into a common market-based matter because patients are vulnerable and cannot shop around for their best deal, like for commodities, and clinicians are always their ultimate reference. So the physician-patient relationship must still be viewed like that of a principal-agent, and further speculation on PE will hardly add value to the theoretical debate.

Trying to build bridges between the different disciplinary approaches, we can finally offer a practical proposal to roughly estimate the levels of inequalities and potential waste inside a health-care system. Assuming that physicians are the most informed patients when they or members of their families fall ill [41], and feel the same emotions as any other patient [42], a useful European observatory project could be set up to permanently compare their health-care patterns of consumption with the general population. To our knowledge, this was already done in the early 1990s only in Switzerland for some common surgical procedures [43], and physicians turned out to have much lower rates of surgery than the general population.

Funding No sources of funding were used to conduct this study or prepare this manuscript.

\section{Compliance with ethical standards}

Conflict of interest Anna Padula and Livio Garattini have no conflicts of interest that are directly relevant to this article.

\section{References}

1. Garattini, L., Curto, A., Freemantle, N.: Pharmaceutical price schemes in Europe: time for a 'continental' one? Pharmacoeconomics 34(5), 423-426 (2016) 
2. Holmström, I., Röing, M.: The relation between patient-centeredness and patient empowerment: a discussion on concepts. Patient Educ. Couns. 79(2), 167-172 (2010)

3. Cerezo, P.G., Juvé-Udina, M.E., Delgado-Hito, P.: Concepts and measures of patient empowerment: a comprehensive review. Rev. Esc. Enferm. USP. 50(4), 667-674 (2016)

4. Feste, C.: A practical look at patient empowerment. Diabetes Care 15(7), 922-925 (1992)

5. Aujoulat, I., d'Hoore, W., Deccache, A.: Patient empowerment in theory and practice: polysemy or cacophony? Patient Educ. Couns. 66(1), 13-20 (2007)

6. Bravo, P., Edwards, A., Barr, P.J., Scholl, I., Elwyn, G., McAllister, M.: Conceptualising patient empowerment: a mixed methods study. BMC Health Serv. Res. 15, 252 (2015)

7. Anderson, R.M., Funnell, M.M., Butler, P.M., Arnold, M.S., Fitzgerald, J.T., Feste, C.C.: Patient empowerment. Results of a randomized controlled trial. Diabetes Care 18(7), 943-949 (1995)

8. Asimakopoulou, K., Gilbert, D., Newton, P., Scambler, S.: Back to basics: re-examining the role of PE in diabetes. Patient Educ. Couns. 86(3), 281-283 (2012)

9. Castro, E.M., Van Regenmortel, T., Vanhaecht, K., Sermeus, W., Van Hecke, A.: Patient empowerment, patient participation and patient-centeredness in hospital care: a concept analysis based on a literature review. Patient Educ. Couns. 99(12), 1923-1939 (2016)

10. Roberts, K.J.: Patient empowerment in the United States: a critical commentary. Health Expect. 2(2), 82-92 (1999)

11. Funnell, M.M., Anderson, R.M., Arnold, M.S., Barr, P.A., Donnelly, M., Johnson, P.D., Taylor-Moon, D., White, N.H.: Empowerment: an idea whose time has come in diabetes education. Diabetes Educ. 17(1), 37-41 (1991)

12. Varming, A.R., Hansen, U.M., Andrésdóttir, G., Husted, G.R., Willaing, I.: Empowerment, motivation, and medical adherence (EMMA): the feasibility of a program for patient-centered consultations to support medication adherence and blood glucose control in adults with type 2 diabetes. Patient Prefer. Adherence 9, 1243-1253 (2015)

13. Donaldson, L.: Expert patients usher in a new era of opportunity for the NHS. BMJ 326(7402), 1279-1280 (2003)

14. Garcimartin, P., Comin-Colet, J., Delgado-Hito, P., Badosa-Marcé, N., Linas-Alonso, A.: Transcultural adaptation and validation of the patient empowerment in long-term conditions questionnaire. BMC Health Serv. Res. 17(1), 324 (2017)

15. Anonymous. Patient empowerment-who empowers whom? Lancet. 2012;379(9827): 1677

16. Barr, P.J., Scholl, I., Bravo, P., Faber, M.J., Elwyn, G., McAllister, M.: Assessment of patient empowerment-a systematic review of measures. PLoS One 10(5), e0126553 (2015)

17. Risling, T., Martinez, J., Young, J., Thorp-Froslie, N.: Evaluating Patient Empowerment in Association With eHealth Technology: scoping review. J. Med. Internet Res. 19(9), e329 (2017)

18. Fumagalli, L.P., Radaelli, G., Lettieri, E., Bertele', P., Masella, C.: Patient empowerment and its neighbours: clarifying the boundaries and their mutual relationships. Health Policy 119(3), 384-394 (2015)

19. Schulz, P.J., Nakamoto, K.: Health literacy and patient empowerment in health communication: the importance of separating conjoined twins. Patient Educ. Couns. 90(1), 4-11 (2013)

20. Coulter, A., Ellins, J.: Effectiveness of strategies for informing, educating and involving patients. BMJ 335(7609), 24-27 (2007)

21. Funnell, M.M.: Patient empowerment: what does it really mean? Patient Educ. Couns. 99(12), 1921-1922 (2016)
22. McAllister, M., Dearing, A.: Patient reported outcomes and patient empowerment in clinical genetics services. Clin. Genet. 88(2), 114-121 (2015)

23. Palumbo, R.: The Bright and the Dark Side of Patient Empowerment. Springer, New York (2017)

24. Lewin, D., Piper, S.: Patient empowerment within a coronary care unit: insights for health professionals drawn from a patient satisfaction survey. Intensive Crit. Care Nurs. 23(2), 81-90 (2007)

25. de Haes, H., Koedoot, N.: Patient centered decision making in palliative cancer treatment: a world of paradoxes. Patient Educ. Couns. 508(1), 43-49 (2003)

26. Loukanova, S., Molnar, R., Bridges, J.F.: Promoting patient empowerment in the healthcare system: highlighting the need for patient-centered drug policy. Expert Rev Pharmacoecon Outcomes Res. 7(3), 281-289 (2007)

27. Garattini, L., Casadei, G.: Health technology assessment: for whom the bell tolls? Eur J Health Econ. 9(4), 311-312 (2008)

28. Christensen, M., Hewitt-Taylor, J.: Patient empowerment: does it still occur in the ICU? Intensive Crit. Care Nurs. 23(3), 156-161 (2007)

29. Laverack, G., Wallerstein, N.: Measuring community empowerment: a fresh look at organizational domains. Health Promot. Int. 16(2), 179-185 (2001)

30. Lau, D.H.: Patient empowerment-a patient-centred approach to improve care. Hong Kong Med. J. 8(5), 372-374 (2002)

31. Blackhall, L.J., Murphy, S.T., Frank, G., Michel, V., Azen, S.: Ethnicity and attitudes toward patient autonomy. JAMA 274(10), 820-825 (1995)

32. Toofany, S.: Patient empowerment: myth or reality? Nurs. Manag. (Harrow) 13(6), 18-22 (2006)

33. Jotterand, F., Amodio, A., Elger, B.S.: Patient education as empowerment and self-rebiasing. Med. Health Care Philos. 19(4), 553-561 (2016)

34. English, T., Ribeiro, B.: Should doctor assisted dying be legal? BMJ 360, k562 (2018). https://doi.org/10.1136/bmj.k562

35. Hewitt-Taylor, J.: Challenging the balance of power: patient empowerment. Nurs. Stand. 18(22), 33-37 (2004)

36. Ferguson, T.: From patients to end-users. BMJ 324(7337), 555$556(2003)$

37. Tomes, N.: Patient empowerment and the dilemmas of late-modern medicalisation. Lancet 369(9562), 698-700 (2007)

38. Colombo, C., Moja, L., Gonzalez-Lorenzo, M., Liberati, A., Mosconi, P.: Patient empowerment as a component of health system reforms: rights, benefits and vested interests. Intern. Emerg. Med. 7(2), 183-187 (2012)

39. Deccache, A., van Ballekom, K.: From patient compliance to empowerment and consumer's choice: evolution or regression? An overview of patient education in French speaking European countries. Patient Educ. Couns. 78(3), 282-287 (2010)

40. Goldstein, M.M., Bowers, D.G.: The patient as consumer: empowerment or commodification? Currents in contemporary bioethics. J. Law Med. Ethics. 43(1), 162-165 (2015)

41. Zorab, J.: Patient empowerment. J. R. Soc. Med. 97(4), 207-208 (2004)

42. Rule, A.R.L.: I am that parent. JAMA. 319(5), 445 (2018)

43. Domenighetti, G., Casabianca, A., Gutzwiller, F., Martinoli, S.: Revisiting the most informed consumer of surgical services. The physician-patient. Int. J. Technol. Assess. Health Care 9(4), 505513 (1993) 